\title{
What happens to COPD patients before an admission with exacerbation?
}

\author{
Robert Stone ${ }^{1}$, Derek Lowe ${ }^{2}$, Rhona Buckingham ${ }^{3}$, Nancy Pursey ${ }^{4}$, Jonathan Potter ${ }^{5}$ and \\ C. Michael Roberts ${ }^{6}$ \\ ${ }^{1}$ Consultant Respiratory Physician, Taunton and Somerset NHS Foundation Trust, Associate Director \\ COPD Programme Clinical Effectiveness and Evaluation Unit, Royal College of Physicians, London, UK \\ ${ }^{2}$ Medical Statistician, Clinical Effectiveness and Evaluation Unit, Royal College of Physicians, London, UK \\ ${ }^{3}$ Manager, Clinical Effectiveness and Evaluation Unit, Royal College of Physicians, London, UK \\ ${ }^{4}$ Project Manager, Clinical Evaluation and Effectiveness Unit, Royal College of Physicians, London, UK \\ ${ }^{5}$ Medical Director, Clinical Effectiveness and Evaluation Unit, Royal College of Physicians, London, UK \\ ${ }^{6}$ Consultant Respiratory Physician, Whipps Cross University Hospital, London and Associate Director \\ COPD Programme Clinical Effectiveness and Evaluation Unit, Royal College of Physicians, London, UK
}

\begin{abstract}
Aim: To obtain patient-generated data relating to the management of their chronic obstructive pulmonary disease (COPD) in Primary Care before hospitalisation with exacerbation. Background: Previous audits of COPD have shown high rates of hospital admission and readmission. There is significant interest in understanding the reasons so that useful preventative strategies may be developed. As part of the 2008 UK COPD audit, which comprised 9716 cases of COPD admission across $97 \%$ of acute units, we obtained a sample of patient-generated data to assess understanding of COPD, use of healthcare resources, access to care and self-management in Primary Care prior to hospitalisation with exacerbation. We anticipated the data would provide useful insight for directing improvement strategies. Method: A paper-based, anonymised survey was completed by patients identified as having exacerbation by participating hospital teams. Response rate was an estimated $46 \%$. Findings: Understanding and awareness of COPD was very variable. Patients noticed symptoms of COPD exacerbation, particularly change in sputum, for some time prior to hospitalisation but tended not to react promptly to these changes. A minority had self-care plans, many bypassed Primary Care Services and there was variable access to a named health professional or advice. Patients using home oxygen and nebulisers were at particular risk of admission. Conclusion: We conclude these sick patients use a lot of resources and the data suggest a need to support and educate them in the proactive management of exacerbation. There needs to be better 'exacerbation planning' so patients know how to recognise and treat flare-up but also whom to contact in the event of decline. Targetted support should be considered for the most vulnerable, particularly those using home oxygen and nebulisers, who have very high rates of hospitalisation.
\end{abstract}

Keywords: avoiding hospital admission; chronic obstructive pulmonary disease; primary care; recognising exacerbation; self-care; UK patient survey

Received 26 June 2011; revised 6 February 2012; accepted 29 February 2012;

first published online 24 April 2012

Correspondence to: Dr Robert Stone, Somerset Lung Centre, Taunton and Somerset NHS Foundation Trust, Taunton TA1 5DA, UK. Email: Robert.stone@tst.nhs.uk

(C) Cambridge University Press 2012

\section{Introduction}

Previous UK audits of chronic obstructive pulmonary disease (COPD) undertaken in 1997, 
2001 and 2003 (Roberts et al., 2002; Royal College of Physicians and British Thoracic Society, 2003; Royal College of Physicians, British Thoracic Society and British Lung Foundation, 2003) examined the organisation and quality of acute hospital services but did not engage patient opinion or extend their scope into primary care. Given this context, we undertook surveys of patients, General Practitioners and Primary Care Organisations within the 2008 UK COPD audit to understand more about the organisation of community services and the impact COPD has upon these groups. We wished in particular to assess the period before hospitalisation, when patients noticed the symptoms of exacerbation and how they accessed care. Specifically, we wanted to obtain data from patients that might inform the development of self-care and community COPD services around the prevention of hospital admission. We present here some results from the patient questionnaire with specific reference to understanding of disease, accessing care, selfmanagement and oxygen/nebuliser use.

\section{Methods}

Methodology and reports of the 2008 National COPD Audit have been published elsewhere (Royal College of Physicians, British Thoracic Society and British Lung Foundation reports, 2008a; 2008b; 2008c; 2008d; 2008e). UK hospital units admitting unselected emergency medical admissions were asked to identify prospectively up to 60 consecutive cases of COPD exacerbation between March and May 2008, and then to audit retrospectively their in-hospital care and outcomes 90 days following the index admission. Acute hospital teams were asked to request 30 of these patients to complete a survey about their COPD as they approached discharge from hospital. Survey responses were returned directly to the Project Team at the Clinical Effectiveness and Evaluation Unit (CEEU) within pre-paid envelopes. It is not known exactly how many survey questionnaires were used, and consequently the response rate was estimated using an assumed denominator made up of 30 discharges each for units with at least 30 discharges in the clinical audit, and all discharges for units with fewer than 30 discharges.
The patient questionnaire comprised 21 questions (available at http://www.rcplondon.ac.uk/ clinical-standards/ceeu/Current-work/ncrop/Pages/ Resources.aspx, see Appendix A). It was compiled following consultation with multidisciplinary professional groups and patients attending support meetings run by the British Lung Foundation (BLF). It was designed to determine how patients access COPD care, to understand their use of primary care services in the period leading up to hospitalisation with exacerbation, to assess how patients self-manage their condition, which patients might benefit from enhanced case management and the potential for interventions to prevent hospital admission.

Fisher's exact test was used to compare between survey responses of patients stating they used both oxygen and nebuliser at home and survey responses of other patients.

\section{Results}

In the clinical audit 9716 cases of exacerbation were submitted by 232 NHS hospital units taking acute COPD admissions, an estimated unit participation of $97 \%$. A total of 2861 analysable patient survey returns were received from 221 units (median 13, IQR 8-17 per unit), the estimated response being $46 \%(2861 / 6255)$. Gender was not stated by 198 (7\%) patients but, when known, 1314 (49\%) were female and 1349 (51\%) were male. Mean age was 72 years (males 71 years, females 72 years, gender not stated 71 years). Just over onethird of patients $(1043,36 \%)$ lived alone without support (30\% male, $44 \%$ female). Nearly all patients $(2369,83 \%)$ reported having flare-ups of their chest condition a number of times a year, while $905(32 \%)$ were using oxygen and 1386 (48\%) were using nebulisers at home.

Reported understanding of COPD was good, $85 \%$ of patients stating they knew what COPD stood for and $79 \%$ knowing they had it before the admission (Table 1). Stated understanding of medications was also very good $(81 \%)$ and $68 \%$ of patients reported infection occurring in the month prior to their admission. Just over half $(57 \%)$ of these cases also noticed a change in the colour or amount of sputum but, importantly, this change was often noticed several days before hospitalisation (Table 2). Only $23 \%$ of patients 


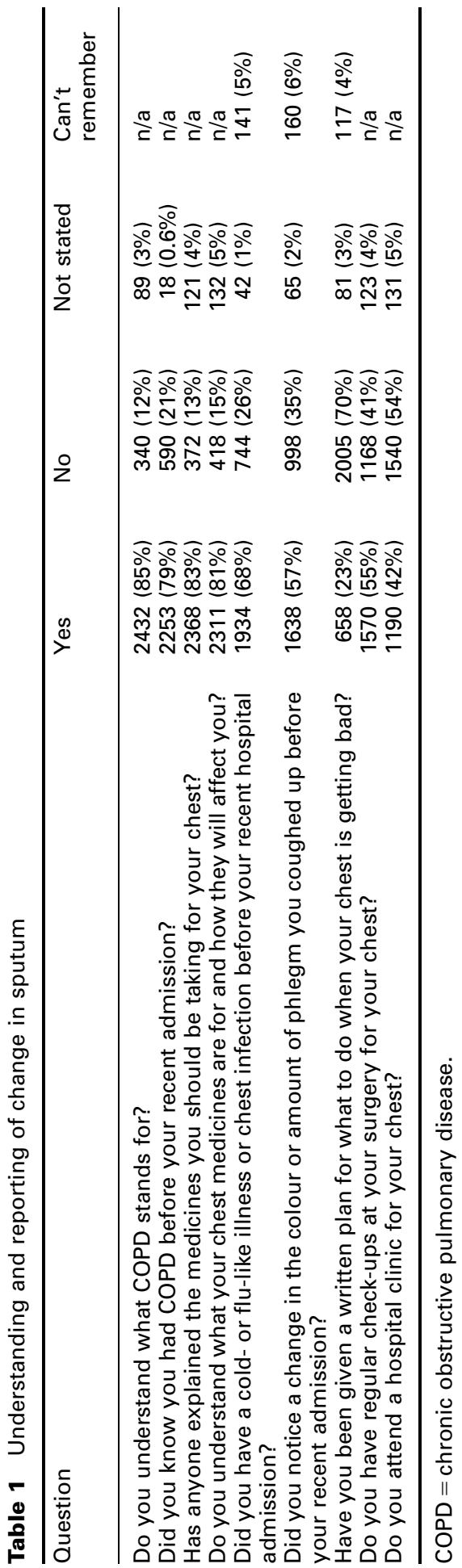

Table 2 Changes in sputum

Did you notice a change in the colour or amount of phlegm you coughed up before Yes your recent admission to hospital?

If 'yes', for how long before the admission did you notice this change?

- $<48 \mathrm{~h}$

$348(21 \%)$

- Between two and five days

$747(46 \%)$

- $>6$ days

$426(26 \%)$

- Can't remember

$106(6 \%)$

- Not stated

$11(0.7 \%)$

had been given a written plan for what to do when bad (Table 1) despite stated attendance at either the GP surgery $(55 \%)$ or chest clinic $(42 \%)$.

Prior to this episode, most of these patients $(60 \%)$ had been admitted to hospital within the last year and a total of $74 \%$ had been previously admitted at some time (Table 3). However, less than half were likely to see their General Practitioner (GP) immediately or the Practice Nurse when their chest was bad and contact with respiratory nurses $(9 \%)$ was particularly low (Table 4). Only one-third of patients saw their GP prior to the current admission, with $53 \%$ going to Accident \& Emergency (A\&E) directly and another $16 \%$ getting to hospital by other means. When their chest was getting bad, $1640(57 \%)$ said they would seek advice over the phone from their GP, respiratory nurse or hospital doctor. A quarter of such patients $(428,26 \%)$ had direct telephone access to professional advice and another 889 (54\%) felt they were able to get telephone advice the same day but some 323 $(20 \%)$ felt either that it would take longer than this or were not sure.

Both oxygen and nebulised bronchodilator were used at home by 675 (24\%) patients (Table 5). Almost all (92\%) of these 675 cases had been admitted with COPD exacerbation previously, and $520(77 \%)$ reported an admission within the previous 12 months. More patients in this group described frequent exacerbation (94\% versus $79 \%$ ) yet there was little difference in the proportion given a written plan for managing exacerbation (29\% versus $21 \%)$. Although more patients on oxygen and nebulisers knew they had COPD prior to the recent admission ( $91 \%$ versus $75 \%$ ), stated understanding of COPD was not greatly different ( $88 \%$ versus $84 \%$ ) and only $29 \%$ of those previously admitted had rescue medication at home 
Table 3 Previous admissions

\begin{tabular}{|c|c|c|c|c|}
\hline Question & Yes & No & $\begin{array}{l}\text { Not } \\
\text { stated }\end{array}$ & Can't remember \\
\hline $\begin{array}{l}\text { Have you been admitted to hospital for your } \\
\text { chest (COPD) within the last year? }\end{array}$ & $1724(60 \%)$ & $1023(36 \%)$ & $114(4 \%)$ & $\mathrm{n} / \mathrm{a}$ \\
\hline $\begin{array}{l}\text { Was this the first time you have been } \\
\text { admitted to hospital with COPD (bad chest)? }\end{array}$ & 709 (25\%) & $2124(74 \%)$ & $28(1 \%)$ & $\mathrm{n} / \mathrm{a}$ \\
\hline $\begin{array}{l}\text { When your chest is bad do you seek advice } \\
\text { over the 'phone from your GP, respiratory } \\
\text { nurse or hospital doctor? }\end{array}$ & $1640(57 \%)$ & $846(30 \%)$ & $90(3 \%)$ & $\begin{array}{l}285(10 \%) \text { answered } \\
\text { an option: 'my chest is } \\
\text { only recently bad' }\end{array}$ \\
\hline
\end{tabular}

COPD $=$ chronic obstructive pulmonary disease.

Table 4 How patients access care

\begin{tabular}{|c|c|}
\hline $\begin{array}{l}\text { If previously admitted with COPD, } \\
\text { what do you usually do when your } \\
\text { chest is bad? } \\
\text { Contact GP immediately } \\
\text { Contact a respiratory nurse } \\
\text { Wait a bit and contact your doctor } \\
\text { Go to a hospital rather than your } \\
\text { doctor } \\
\text { I have antibiotics or steroids to take } \\
\text { at home }\end{array}$ & $\begin{array}{l}\mathrm{N}=2124 \text { with } \\
\quad \text { previous } \\
\text { admission } \\
685(32 \%) \\
191(9 \%) \\
608(29 \%) \\
465(22 \%) \\
503(24 \%)\end{array}$ \\
\hline $\begin{array}{l}\text { On this occasion, by what route were } \\
\text { you admitted to hospital for your } \\
\text { chest? } \\
\text { I saw my GP and (s)he sent me to } \\
\text { hospital } \\
\text { I went to casualty (A\&E) under my } \\
\text { own steam and not in an ambulance } \\
\text { I did not see my GP but called an } \\
\text { ambulance } \\
\text { Other }\end{array}$ & $\begin{array}{l}\text { All } 2861 \text { survey } \\
\text { patients } \\
962(34 \%) \\
333(12 \%) \\
1176(41 \%) \\
461(16 \%)\end{array}$ \\
\hline $\begin{array}{l}\text { depending mainly on how severe their } \\
\text { b Patients could choose as many option } \\
\text { their situation. } \\
{ }^{c} \text { Other included situations such as spou } \\
\text { ambulance, family member called ambu } \\
\text { called ambulance, doctor advised patien } \\
\text { ambulance but did not see patient, helpl } \\
\text { patient to call ambulance, care-line advis } \\
\text { ambulance, out of hours service sent pa } \\
\text { paramedics sent patient to hospital, adm } \\
\text { saw GP and treated but needed admissi }\end{array}$ & $\begin{array}{l}\text { sease. } \\
\text { ption, these } \\
\text { lest was. } \\
\text { as applied to } \\
\text { called } \\
\text { ce, warden } \\
\text { call } \\
\text { advised } \\
\text { patient to call } \\
\text { nt to hospital, } \\
\text { ed via clinic, } \\
\text { at a later stage. }\end{array}$ \\
\hline
\end{tabular}

compared to $22 \%$ of the rest. The oxygen and nebuliser patients were more aware of changes in sputum $(63 \%$ versus $56 \%)$.

Patients using oxygen and nebulisers (Table 5) seemed better at accessing respiratory nurses during exacerbation (16\% versus $6 \%)$ and were less likely to wait before seeking help (22\% versus $31 \%)$. A greater proportion called an ambulance before the admission (47\% versus 39\%) and more sought telephone advice (75\% versus $52 \%$ ). Of these, more had a direct access number to phone (33\% versus $23 \%$ ). For those without direct access, more from this group felt they could obtain telephone advice the same day $(80 \%$ versus $71 \%)$.

\section{Discussion}

\section{Main findings}

To our knowledge, this is the first national survey enquiring about COPD care in the period leading up to an acute hospital admission. The data show such a study of COPD patients is feasible and can yield helpful information from a large number of cases. The responses suggest a population that uses a lot of healthcare resources, has severe and frequently exacerbating COPD. Most patients knew they had COPD, knew what it was and had been in hospital with exacerbation before. Although patients reported good understanding of disease, symptoms were often present for some time prior to admission. Infection was a frequent event in the month before admission and there was often a period of sputum production prior to presentation with exacerbation. Self-management of exacerbation seemed low, despite $55 \%$ receiving regular review at surgery and $42 \%$ in hospital chest clinics. When sick, patients tended to use hospital services instead of primary care and came to hospital by various means. Few patients used specialist nurses as a source of support, and access to telephone 
Table 5 Responses of those stating oxygen and nebuliser use at home

\begin{tabular}{|c|c|c|c|}
\hline Question & $\begin{array}{l}\text { Oxygen and } \\
\text { nebuliser }(n=675)\end{array}$ & $\begin{array}{l}\text { Rest, including not } \\
\text { known }(n=2186)\end{array}$ & $P$-value ${ }^{a}$ \\
\hline Do you understand what COPD stands for? & $594(88 \%)$ & $1838(84 \%)$ & 0.02 \\
\hline $\begin{array}{l}\text { Did you know you had COPD before your recent hospital } \\
\text { admission? }\end{array}$ & $615(91 \%)$ & $1638(75 \%)$ & $<0.001$ \\
\hline $\begin{array}{l}\text { Was this the first time you had been admitted to hospital } \\
\text { with COPD (bad chest)? }\end{array}$ & $53(8 \%)$ & $656(30 \%)$ & $<0.001$ \\
\hline - If no, do you usually contact a respiratory nurse? & $98 / 616(16 \%)$ & $93 / 1508(6 \%)$ & $<0.001$ \\
\hline - If no, do you wait a bit and contact your GP? & $135 / 616(22 \%)$ & $473 / 1508(31 \%)$ & $<0.001$ \\
\hline - If no, do you go to hospital rather than your doctor (GP)? & $133 / 616(22 \%)$ & $332 / 1508(22 \%)$ & 0.86 \\
\hline - If no, do you phone an NHS Helpline? & $30 / 616(4.9 \%)$ & $68 / 1508(4.5 \%)$ & 0.73 \\
\hline $\begin{array}{l}\text { - If no, do you have antibiotics and/or steroids you can take } \\
\text { when bad? }\end{array}$ & $176 / 616(29 \%)$ & $327 / 1508(22 \%)$ & 0.001 \\
\hline I saw my GP and (s)he sent me to hospital & $189(28 \%)$ & $773(35 \%)$ & $<0.001$ \\
\hline I went to $A \& E$ under my own steam & $56(8 \%)$ & $277(13 \%)$ & 0.002 \\
\hline I did not see a GP but called an ambulance & $319(47 \%)$ & $857(39 \%)$ & $<0.001$ \\
\hline $\begin{array}{l}\text { Did you have a cold- or flu-like illness or chest infection } \\
\text { during the month before your recent admission to hospital? }\end{array}$ & $461(68 \%)$ & $1473(67 \%)$ & 0.67 \\
\hline $\begin{array}{l}\text { Did you notice a change in the colour or amount of phlegm } \\
\text { you coughed up before your recent admission to hospital? }\end{array}$ & $422(63 \%)$ & $1216(56 \%)$ & 0.002 \\
\hline $\begin{array}{l}\text { Has anyone explained the medicines you should be taking } \\
\text { for your chest? }\end{array}$ & $591(88 \%)$ & $1777(81 \%)$ & $<0.001$ \\
\hline $\begin{array}{l}\text { Do you understand what your chest medicines are for and } \\
\text { how they will affect you? }\end{array}$ & $579(86 \%)$ & $1732(79 \%)$ & $<0.001$ \\
\hline Do you live on your own? & $212(31 \%)$ & $831(38 \%)$ & 0.002 \\
\hline $\begin{array}{l}\text { Have you been admitted to hospital for your chest (COPD) } \\
\text { within the last year? }\end{array}$ & $520(77 \%)$ & $1204(55 \%)$ & $<0.001$ \\
\hline $\begin{array}{l}\text { How often do you get flare-ups of your chest condition: a } \\
\text { number of times a year? }\end{array}$ & $635(94 \%)$ & $1734(79 \%)$ & $<0.001$ \\
\hline $\begin{array}{l}\text { Have you been given a written plan for what to do when your } \\
\text { chest is getting bad? }\end{array}$ & $197(29 \%)$ & $461(21 \%)$ & $<0.001$ \\
\hline $\begin{array}{l}\text { When your chest is getting bad do you seek advice over the } \\
\text { phone from your GP, respiratory nurse or hospital doctor? }\end{array}$ & $505(75 \%)$ & $1135(52 \%)$ & $<0.001$ \\
\hline $\begin{array}{l}\text { - If yes, do you have a number that puts you through to } \\
\text { someone who advises you? }\end{array}$ & 168/505 (33\%) & $260 / 1135$ (23\%) & $<0.001$ \\
\hline $\begin{array}{l}\text { - If patient did not have a direct access number could they } \\
\text { speak to someone and get advice the same morning/ } \\
\text { afternoon? }\end{array}$ & $269 / 337$ (80\%) & $620 / 875(71 \%)$ & 0.001 \\
\hline
\end{tabular}

COPD = chronic obstructive pulmonary disease; NHS = National Health Service.

${ }^{\text {a }}$ Fishers exact test.

advice was patchy, even for patients on oxygen and/or nebulisers. Many patients used oxygen and nebulisers and this group seemed at particular risk of admission.

\section{Limitations}

There are several limitations to our study, the first being the survey was undertaken in 2008. However, we have no reason or evidence to suggest the findings would be any different now, the need to improve self-care, recognition and management of exacerbation being highlighted in recent documents published by both the Department of Health in England (DH, 2011) and National Institute of Health and Clinical Excellence (NICE, 2011). Second, while it may have been entirely appropriate for patients to take themselves to hospital rather than use community services at the time of survey, we did not ask why they did so and neither did we enquire about the timing of admission. A better understanding of data reliability could have been achieved by calculating kappa values, having asked a second 
researcher to review sample responses, and we would intend to do this in future surveys. Neither did we link individual spirometric data to survey responses although these were all cases from the clinical audit, in which mean \% predicted $\mathrm{FEV}_{1}$ was 38\% (Royal College of Physicians, British Thoracic Society and British Lung Foundation reports, 2008a; 2008b; 2008c; 2008d; 2008e).

\section{Significance of findings}

The data suggest we need to help patients improve their recognition of exacerbation, selfcare and access to healthcare advice. Although the best method, timing or setting is not established, self-management education in COPD patients is associated with a reduction in hospital admissions without affecting other outcome parameters (Bourbeau et al., 2003; Effing et al., 2007). Seemungal et al. (2000) demonstrated a subtle rise in symptoms in the period prior to onset of exacerbation and our data also imply there should be an emphasis upon recognising infection as a potential trigger for exacerbation, prompting action when sputum changes occur. Notably, only a quarter of our patients had access to rescue medication at home, yet COPD education delivered in primary care, taking as little as $2 \mathrm{~h}$, increases objective measures of diseasespecific knowledge (Hill et al., 2010); it would seem reasonable to suggest such packages include specific advice about the recognition of exacerbation, how to act at its onset, what medication is effective, how to use it and how to access advice.

It was also unclear why so few patients normally contacted a respiratory nurse during exacerbation. Only $57 \%$ of our cohort sought telephone advice but recent evidence suggests such a service may reduce hospital admission (Robert et al., 2008). Nurse-led telephone and self-management advice reduces unscheduled visits and mortality in patients recently admitted with COPD exacerbation (Sridhar et al., 2008). Nurse-led clinics are reported to reduce exacerbation rates (Rootmensen et al., 2008).

There is also scope for better communication, co-ordination and sharing of advice between primary and secondary care services, given that many patients were attending for review at both their GP surgery and a chest clinic. This would seem particularly true of patients receiving oxygen and nebulisers, of whom $77 \%$ had been admitted to hospital within the previous 12 months; a more consistent approach to case-managing this most vulnerable of groups would seem sensible. Although we did not investigate the reasons for such high admission rates in these patients, they reported having significantly more exacerbations and a greater propensity to seek telephone advice, yet had similar levels of self-management and access to care as the rest of the population. Many groups are developing strategies that place admission avoidance at their heart and have developed community COPD teams for this purpose (Royal College of Physicians, British Thoracic Society and British Lung Foundation reports, 2008a; 2008b; 2008c; 2008d; 2008e). Our data suggest interface services that integrate well with the primary and secondary care teams, but also put self-care, patient education and case-management of the most vulnerable at their core, would be beneficial. As yet, however, there is limited evidence in the United Kingdom to suggest interface services are looking to broader strategic issues and local educational needs (Pinnock et al., 2009).

\section{Future work}

There is much to be explored as a consequence of this work. Given the data suggest patients may avoid hospital admission by acting promptly when sputum changes occur, the formal assessment of a self-care plan that places identification of sputum change at its heart would be useful. The high use of primary care services in the period leading up to hospital admission also implies COPD patients need betterplanned links into the wider care process and improved access to rapid advice from healthcare professionals, particularly nurses. It would be valuable to study the specific effect of an available 'named contact' on hospital admissions and to undertake a systematic evaluation of enhanced casemanagement (eg by Tele-Health) for those with the most severe disease, that is, patients on oxygen and nebulisers. Further study of the precise reasons for admission in this group would be useful.

Future surveys would benefit from exploring in greater detail the nature of patients' understanding of disease and self-care, and specifically to ask whether they enacted a plan that failed or felt their plan was insufficient. Although patientreported understanding of disease and medication 
was very good (Table 1), it would be of interest to consider the $15 \%$ who did not know what COPD stood for, the $21 \%$ who did not know they had it before their admission and the $19 \%$ whose stated understanding was not very good and to study the relationships between these groups, patient outcomes and use of healthcare resource.

\section{Acknowledgements}

The 2008 UK COPD audit was supported by a grant from the Health Foundation.

\section{Supplementary materials}

For supplementary material referred to in this article, please visit http://dx.doi.org/doi:10.1017/ S1463423612000187

\section{References}

Bourbeau, J., Julien, M., Maltais, F., Rouleau, M., Beaupre, A., Begin, R., Renzi, P., Nault, D., Borycki, E., Schwartzman, K., Singh, R. and Collet, J.-P. 2003: Reduction of hospital utilisation in patients with Chronic Obstructive Pulmonary Disease: a disease-specific self-management intervention. Archives of Internal Medicine 163, 585-91.

Department of Health (DH). 2011: An outcomes strategy for people with chronic obstructive pulmonary disease (COPD) and asthma in England 2011. Retrieved from http://www.dh. gov.uk/en/Publicationsandstatistics/Publications/Publications PolicyAndGuidance/DH_127974

Effing, T., Monninkhof, E.M., van der Valk, P.D., van der Palen, J., van Herwaarden, C.L., Partridge, M.R., Walters, E.H. and Zielhuis, G.G. 2007: Self-management education for patients with chronic obstructive pulmonary disease. Cochrane Database of Systemic Reviews 4, CD002990.

Hill, K., Mangovski-Alzamora, S., Guyatt, G., Heels Ansdell, D., Bragaglia, P., Tamari, L., Jones, K. and Goldstein, R. 2010: Disease-specific education in the primary care setting increases the knowledge of people with chronic obstructive pulmonary disease: a randomised controlled trial. Patient Education and Counseling 81, 14-18.

NHS National Institute for Health and Clinical Excellence. 2011: Chronic obstructive pulmonary disease (COPD) quality standard. Retrieved from http://www.nice.org.uk/guidance/ qualitystandards/chronicobstructivepulmonarydisease/copd qualitystandard.jsp

Pinnock, H., Huby, G., Tierney, A., Hamilton, S., Powell, A., Kielmann, T. and Sheikh, A. 2009: Is multidisciplinary teamwork the key? A qualitative study of the development of respiratory services in the UK. Journal of the Royal Society of Medicine 102, 378-90.

Robert, M.M., Leeder, S.R. and Robinson, T.D. 2008: Nurse-led 24-h hotline for patients with chronic obstructive pulmonary disease reduces hospital use and is safe. Internal Medicine Journal 38, 334-40.

Roberts, C.M., Ryland, I., Lowe, D., Kelly, Y., Bucknall, C.B. and Pearson, M.G. 2002: Audit of acute admissions with COPD - standards of care and management in the hospital setting. Thorax 57, 137-41.

Rootmensen, G.N., van Keimpema, A.R., Looysen, E.E., van der Schaaf, L., de Haan, R.J. and Jansen, H.M. 2008: The effects of additional care by a pulmonary nurse for asthma and COPD patients at a respiratory clinic: results from a double-blind randomised clinical trial. Patient Education of Counselling 70, 179-86.

Royal College of Physicians of London and British Thoracic Society. 2003: Audit of process and outcome in cases of acute exacerbation of COPD admitted to hospital. Retrieved from http://www.rcplondon.ac.uk/clinical-standards/ ceeu/Current-work/ncrop/Pages/Resources.aspx.

Royal College of Physicians of London, British Thoracic Society and British Lung Foundation. 2003: Report of the 2003 National COPD Audit. Retrieved from http://www. rcplondon.ac.uk/clinical-standards/ceeu/Current-work/ncrop/ Pages/Resources.aspx.

Royal College of Physicians of London, British Thoracic Society and British Lung Foundation. 2008a: Report of the National Chronic Obstructive Pulmonary Disease Audit 2008: clinical audit of COPD exacerbations admitted to acute NHS units. Retrieved from http://www.rcplondon. ac.uk/clinical-standards/ceeu/Current-work/ncrop/Pages/ Resources.aspx.

Royal College of Physicians of London, British Thoracic Society and British Lung Foundation. 2008b: Report of the National Chronic Obstructive Pulmonary Disease Audit 2008: patient survey. Retrieved from http://www.rcplondon. ac.uk/clinical-standards/ceeu/Current-work/ncrop/Pages/ Resources.aspx.

Royal College of Physicians of London, British Thoracic Society and British Lung Foundation. 2008c: Report of the National Chronic Obstructive Pulmonary Disease Audit 2008: survey of COPD care within UK General Practices. Retrieved from http://www.rcplondon.ac.uk/clinical-standards/ ceeu/Current-work/ncrop/Pages/Resources.aspx.

Royal College of Physicians of London, British Thoracic Society and British Lung Foundation. 2008d: Report of the National Chronic Obstructive Pulmonary Disease Audit 2008: resources and organisation of care in acute NHS units across the UK. Retrieved from http://www.rcplondon. ac.uk/clinical-standards/ceeu/Current-work/ncrop/Pages/ Resources.aspx.

Royal College of Physicians of London, British Thoracic Society and British Lung Foundation. 2008e: Report of the National Chronic Obstructive Pulmonary Disease Audit 2008, UK Primary Care Organisations: resources and 
organisation of care. Retrieved from http://www.rcplondon. ac.uk/clinical-standards/ceeu/Current-work/ncrop/Pages/ Resources.aspx.

Seemungal, T.A., Donaldson, G.C., Bhowmik, A., Jeffries, D.J. and Wedzicha, J.A. 2000: Time-course and recovery of exacerbations in patients with chronic obstructive pulmonary disease. American Journal of Respiratory and Critical Care Medicine 161, 1608-13.

Sridhar, M., Taylor, R., Dawson, S., Roberts, N.J. and Partridge, M.R. 2008: A nurse-led intermediate care package in patients who have been hospitalized with an acute exacerbation of chronic obstructive pulmonary disease. Thorax 63, 187-89. 